\title{
Effects of different proportions of inorganic fertilizer and organic fertilizer on yield and quality of amaranth
}

\author{
Huashan Lian ${ }^{1, a}$, Liying Ouyang ${ }^{1, b^{*}}, J_{i}$ Liu $^{2, c}$, Liqiong Yang ${ }^{1, d}$ and Panhong \\ Zou $^{1, e}$
}

${ }^{1}$ Chengdu Agricultural college, Chengdu, Sichuan, China

${ }^{2}$ Chengdu Academy of Agriculture and Forestry Sceinces, Chengdu, Sichuan, China

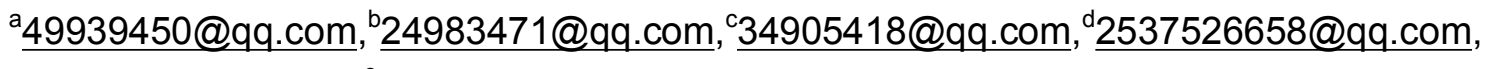
e417402053@qq.com *Corresponding author

Keywords: inorganic fertilizer; organic fertilizers; white amaranth; yield; quality

Abstract: This paper studied the effects of different proportions of inorganic fertilizer and organic fertilizer on yield and quality of amaranth by means of pot experiments. The result shows that when the ratio of organic fertilizer and inorganic fertilizer is $1: 3$, the most beneficial to improve the production of amaranth and improve its quality.

\section{Introduction}

Amaranth is rich in vitamin $\mathrm{C}$, protein and minerals that needed by the body, and it has good medicinal value and nutritional value [1]. Amaranth is a wild vegetable which has good ability of barren resistant, strong drought tolerance, pest resistance capacity [2]. But now because of lots of unreasonable fertilization leads to vegetable yield and quality decline in the vegetables production, which has become a major obstacle to modern agriculture sustainable development [3].

Studies have shown that inorganic fertilizer is a kind of fast, high nutrient chemicals, but too much inorganic fertilizers will lead to high levels of nitrate in vegetables, affecting the quality of vegetables [4]. Organic fertilizers can provide a more comprehensive and lasting nutrients that needed for crop growth and development, but too much also to cause a decline in quality of vegetable [5]. Many studies have shown that organic and inorganic fertilizer can complement each other, which can provide continuous, comprehensive nutrients to the growth of crops, so as to increase crop yield and quality. Wang Yanbo and other studies have shown that after the organic and inorganic fertilizer processing, the yield of spinach is significantly higher than the pure chemical fertilizer and organic fertilizer processing [6]. Zhou found that inorganic and organic fertilizers can be reduced nitrate accumulation, increase yield and quality of lettuce [7]. Mao and other studies have shown that organic and inorganic fertilizer can increase the sugar content of the fruit, increasing vegetables, melons and fruits of the vitamin $\mathrm{C}$ content, improving the quality of fruits and vegetables [8]. Gong and other studies have also shown that organic and inorganic fertilizer treatment nitrate content of vegetables were lower than pure chemical fertilizer, vitamin $\mathrm{C}$ and soluble sugar content is higher than pure fertilizer treatment [9]. However, the way of the test used the organic nitrogen and the fertilization is relatively complex, so there are some limitations in the actual production. Therefore, this experiment by using commercial organic fertilizer, inorganic fertilizer and simple way of topdressing fertilizer to research the influence of different fertilization 
patterns on yield and quality of amaranth to find appropriate and reasonable proportion of combined application and provide theoretical basis to guide the cultivation amaranth as scientific fertilization.

\section{Materials and Methods}

Materials. Experimental soil was taken from Chengdu, sichuan agricultural university campus around, soil organic matter content is $18.8-32.2 \mathrm{~g} \cdot \mathrm{kg}^{-1}$, total nitrogen content is $2.30-4.33 \mathrm{~g} \cdot \mathrm{kg}^{-1}$, total phosphorus content is $13.8 \mathrm{mg} \cdot \mathrm{kg}^{-1}$, total potassium content is $10 \mathrm{mg} \cdot \mathrm{kg}^{-1}$. The test material is "Han sterile white amaranth". The organic matter content of organic fertilizer is $30 \%-40 \%$, Inorganic nitrogen fertilizer use urea (Containing $\mathrm{N}$ 47\%), Phosphate fertilizer use calcium-magnesia phosphate fertilizer (Containing $\mathrm{P}_{2} \mathrm{O}_{5} 12 \%$ ), potash fertilizer use potassium chloride (Containing $\mathrm{K}_{2} \mathrm{O} 60 \%$ ).

Experimental Design. A pot experiment with six treatments (table 1), and 6 pots per treatment was conducted. Calculated by each pot 3 strains of amaranth, fertilization of chemical fertilizer, total $\mathrm{N}$ $30 \mathrm{~g}, \mathrm{P}_{2} \mathrm{O}_{5} 15 \mathrm{~g}, \mathrm{~K}_{2} \mathrm{O} 30 \mathrm{~g}$ and single organic fertilizer need a total of $300 \mathrm{~g}$. Each process is divided into base fertilizer and topdressing, basal fertilizer is $2 / 5$ the total of fertilizer consumption, Fertilizer 3 times and every time the fertilizer quantity is $1 / 5$ the total of fertilizer consumption. Fertilizer mixed with the soil and into the pot standby, the low temperature seed soaking and then plant, after grow two or three true leaf, for the first time fertilizer, a second after $15 \mathrm{~d}$, for the third time after $25 \mathrm{~d}$. After 40 days, measure index.

Table 1 Inorganic fertilizer and organic fertilizer combined application of different ratio

\begin{tabular}{ccc}
\hline treatment & inorganic fertilizer $(\%)$ & organic fertilizers $(\%)$ \\
\hline CK & 0 & 0 \\
1 & 0 & 100 \\
2 & 100 & 0 \\
3 & 75 & 25 \\
4 & 50 & 50 \\
5 & 25 & 75 \\
\hline
\end{tabular}

\section{Results and Discussion}

Chlorophyll content. We can learn from the table 2, treatment 3 content of chlorophyll a and b are significantly greater than every other processing, the lowest content of chlorophyll a and $\mathrm{b}$ is CK. According to the trend of treatment 1, 2, 3, 4, 5 we can know, with the increase of organic fertilizer and the reduce of inorganic fertilizer, the chlorophyll a and $b$ content increased gradually. When use too much fertilizer, chlorophyll $\mathrm{a}$ and $\mathrm{b}$ content reduced. The change trend of chlorophyll $\mathrm{a}$ and $\mathrm{b}$ are almost the same as the total chlorophyll. 
Table 2 Effects of Different proportions of Inorganic Fertilizer and Organic Fertilizer on Chlorophyll content

\begin{tabular}{cccc}
\hline treatment & $\begin{array}{c}\text { Chlorophyll a } \\
\left(\mu \mathrm{g} \cdot \mathrm{g}^{-1}\right)\end{array}$ & $\begin{array}{c}\text { Chlorophyll b } \\
\left(\mu \mathrm{g} \cdot \mathrm{g}^{-1}\right)\end{array}$ & $\begin{array}{c}\text { Chlorophyll a+b } \\
\left(\mu \mathrm{g} \cdot \mathrm{g}^{-1}\right)\end{array}$ \\
\cline { 2 - 4 } $\mathrm{CK}$ & $75.31 \pm 0.50 \mathrm{a}$ & $23.97 \pm 0.78 \mathrm{a}$ & $99.28 \pm 1.28 \mathrm{a}$ \\
1 & $78.18 \pm 0.49 \mathrm{~b}$ & $25.16 \pm 0.55 \mathrm{~b}$ & $103.34 \pm 1.04 \mathrm{~b}$ \\
2 & $84.72 \pm 0.44 \mathrm{~b}$ & $30.85 \pm 0.63 \mathrm{c}$ & $115.57 \pm 1.07 \mathrm{c}$ \\
3 & $93.17 \pm 0.44 \mathrm{c}$ & $33.83 \pm 0.66 \mathrm{~d}$ & $127.00 \pm 1.10 \mathrm{~d}$ \\
4 & $83.79 \pm 0.42 \mathrm{~d}$ & $29.14 \pm 0.70 \mathrm{~d}$ & $112.93 \pm 1.12 \mathrm{e}$ \\
5 & $81.14 \pm 0.48 \mathrm{e}$ & $26.05 \pm 0.54 \mathrm{e}$ & $107.19 \pm 1.02 \mathrm{f}$ \\
\hline
\end{tabular}

Note: Data followed different letters within column indicate significant difference of 0.05 level.

Plant height, fresh weight and leaf area. We can learn from the table, with the different treatment on amaranth the general tends of the plant height, fresh weight per plant and leaf area were all first increased and then decreased together. the greatest impact on plant height and fresh weight per plant of amaranth is treatment 3, the plant height is significantly higher than treatment 4 and 5 , but the difference with treatment 2 was not significant, fresh weight per plant is significantly higher than treatment 2, 4, 5. Through different processing the leaf area of amaranth is different, the largest leaf area is treatment 2, and the difference between treatment 2 and 3 is not significant. So the best combination is treatm

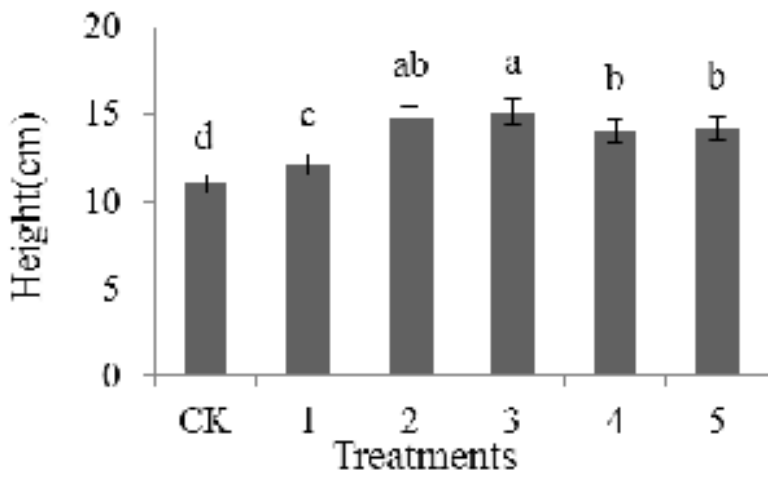

Figure 1 Effects on the plant height

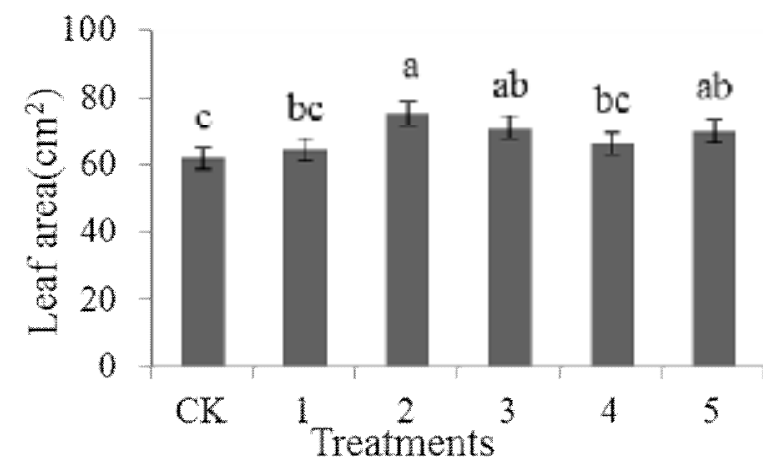

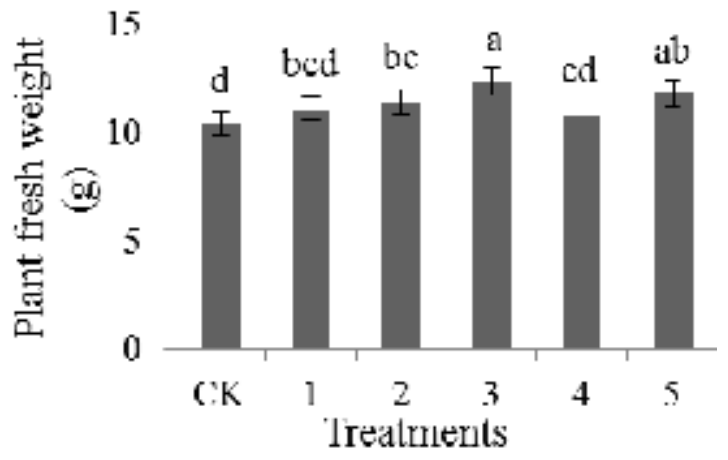

Figure 2 Effect on the fresh weight

Figure 3 Effects on the leaf area

Protein, vitamin C and soluble sugar content. The Fig. 4 shows that the highest protein content is 2 that significantly greater than treatment $1,4,5$ and CK, and there is no significant difference 
between treatment 3. The Fig. 5 shows that the highest vitamin $\mathrm{C}$ content is treatment 3, and different treatments have different vitamin $\mathrm{C}$ content, vitamin $\mathrm{C}$ content with the increase of organic fertilizer to increase, however, when too much organic fertilizer, vitamin $\mathrm{C}$ reduced. From Fig. 6, we find that treatment $3>$ treatment $4>$ treatment $5>$ treatment 1 , the difference of treatment 3 and 2 was significant. With the increase of organic fertilizer, amaranth soluble sugar content increased, but when the organic fertilizer is overmuch, it will inhibit the synthesis of soluble sugar.

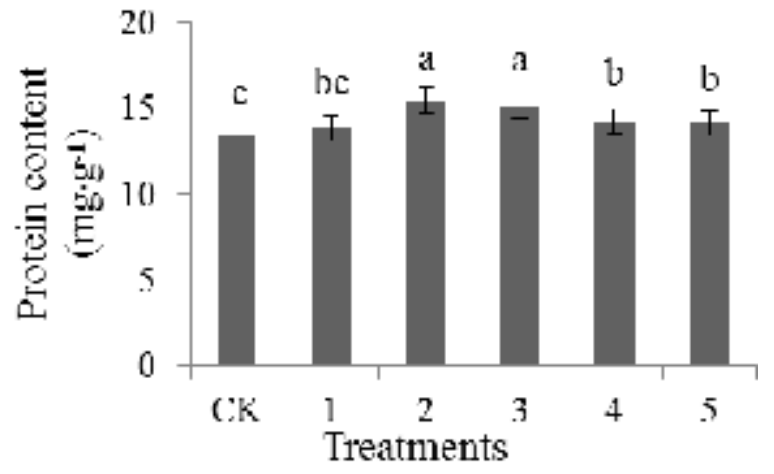

Figure 4 Effect on the protein content

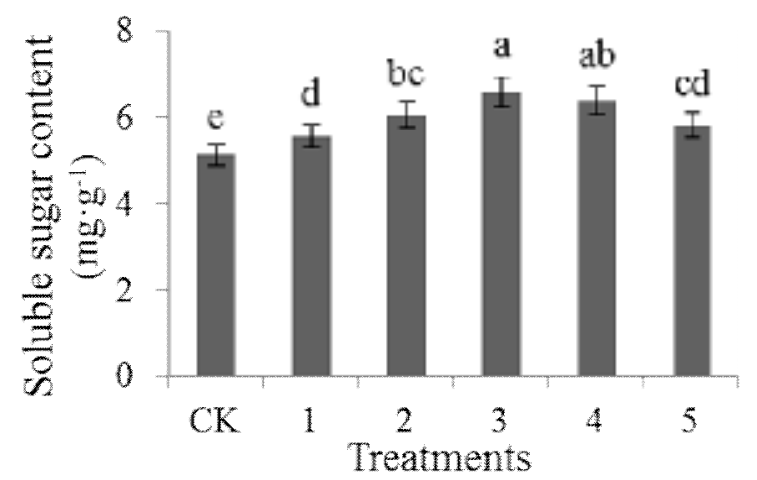

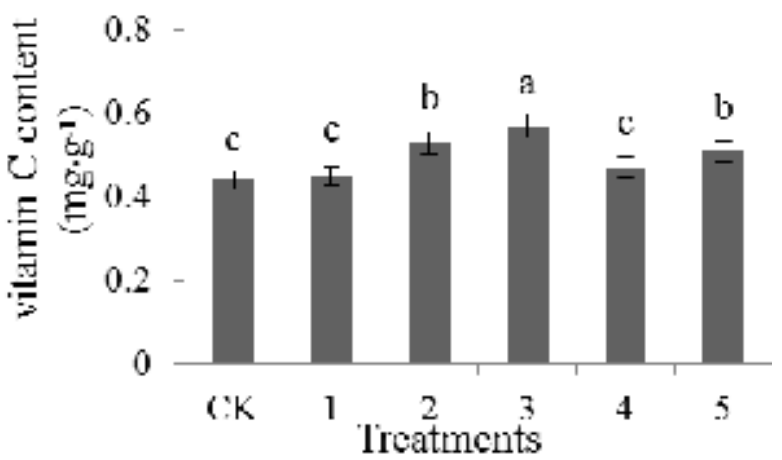

Figure 5 Effect on the vitamin $\mathrm{C}$ content

Figure 6 Effect on the soluble sugar content

Inorganic fertilizer and organic fertilizer with different way have different influence on yield and quality of amaranth. With the increase of organic fertilizer and the reduce of inorganic fertilizer, each index content of amaranth increased gradually, But when too much organic fertilizer, too small inorganic fertilizer, Each index content will reduce gradually, even lower than single inorganic fertilizer treatment. The impact of various treatments on Plant height, fresh weight per plant, vitamin $\mathrm{C}$, soluble sugar, chlorophyll of amaranth that the best treatment is treatment 3 , Followed by Single inorganic fertilizer, And the significant difference between them. The impact of various treatments on Leaf area and protein content of amaranth that the best treatment is Single inorganic fertilizer followed by treatment 3 , but no significant difference between them. So when the ratio of organic fertilizer and inorganic fertilizer is $1: 3$, the most beneficial to improve the production of amaranth and improve its quality.

\section{References}

[1] S. Z. Li: Beijing: people's medical publishing house. 1982.

[2] C. L. Yu, X. C. Gao and Y. T. Yang: Journal of jilin vegetables Vol. 4(1997).

[3] X. Y. Chen, Q. Yan and Z. S. Ming: Journal of hunan agricultural science Vol. 3(2009), p. 
49-50.

[4] R. P. Wang, P. L. Lan and S. Y. Li: Journal of ecological environment Vol. 16.3(2007), p. 1040-1043.

[5] H. H. Li and Z. Y. Wang: Journal of henan agricultural university Vol. 41.1(2007), p. 29-32.

[6] Y. B. Wang: Journal of nanjing agricultural university Vol. 29.3(2006), p. 44-48.

[7] L. Q. Zhou: Journal of guangxi agricultural science Vol. 39.2(2008), p. 192-195.

[8] J. H. Mao: Journal of tianjin agricultural science Vol. 8.3(2002), p. 7-9.

[9] H. R. Gong: Journal of hunan agricultural science Vol. 17(2012), p. 68-69. 